\title{
Application of Technology in Management and Operation of Agricultural Products Supply Chain in Vietnam During the Covid-19 Pandemic
}

\author{
Nguyen Thu Hien, Nguyen Thi Thuy, Vu Huyen Trang and Thanh Cong Ha \\ Business Management Faculty \\ Hanoi University of Industry \\ Cau Dien, Bac Tu Liem District, Ha Noi City, Viet Nam \\ \{nguyenthuhien_qlkd, thuynt4, vuhuyentrang \& conght\}@haui.edu.vn
}

\begin{abstract}
Agricultural products are one of the important products in Vietnam's agricultural industry and contribute significantly to the value of economic growth. Under the direction of the Government, many businesses have taken solutions to remove difficulties in maintaining production, circulation and transportation of goods to ensure the supply of agricultural products during the covid-19 pandemic. In which, the application of technology in chain management and operation is a solution that brings positive effects to Vietnam's agricultural product industry.
\end{abstract}

Index Terms - technology, supply chain, agricultural products.

\section{INTRODUCTION}

$\mathrm{I}^{\mathrm{N}}$ RECENT years, the agricultural product industry is strongly participating in the globalization process with many trade agreements. The covid 19 pandemic with new strains has disrupted global trade, changed the consumption trend of agricultural products and caused the supply chain of agricultural products in Vietnam to be broken. Therefore, the application of technology in management is necessary. In this article, the authors study an overview of technology, its application in the operation and management of agriculture products supply chains in Vietnam and lessons learned from some countries around the world.

\section{Overview}

\section{Agricultural products}

Agricultural products are the main products of the agricultural industry. Agricultural products are the products or semi-finished products of the commodity-producing and growing industry (WTO).

Cash crops is a concept used to refer to agricultural products that farmers produce for the purpose of selling to the market (Nguyen Van Ngoc).

\section{A. Characteristics of agricultural products}

Firstly, varieties, bulky and easily damaged: agricultural products are diverse in types including diversity in varieties, diversity in ecosystems in agriculture [7]. In addition, agricultural products are mainly harvested in the form of fresh products, which are very perishable and difficult to preserve. Therefore, the stages of harvesting, transporting, preserving and processing are very important and play a decisive role in exporting agricultural products to foreign countries.
Secondly, strongly influenced by natural conditions: Land, soil, water and weather conditions are the factors that directly determine the yield and quality of agricultural products. If natural conditions are favorable, it will help plants grow well, give high yields, agricultural products meet the prescribed standards and vice versa [5].

Third, agricultural products are often seasonal: Each crop and plant variety have its own specific climatic conditions to grow [13]. Therefore, the seasonality of agricultural products is clearly shown. Therefore, to ensure the long-term and regular supply of agricultural products, it is necessary to have a good process of preserving and storing goods. If we can do that, the process of supplying goods will be stable and long-term.

Fourth, dispersed and local agricultural products: The production of agricultural products is mainly based on natural and weather conditions, which are specific to the region. Therefore, agricultural products are often dispersed into different production areas based on natural conditions, soil as well as climate of each region. This has made the collection, transportation, storage and processing of goods take more time and cost.

\section{B. Impact of the Covid-19 pandemic on the agricultural product industry}

The Covid-19 pandemic has negatively affected production and harvesting. The export value of many agricultural products tends to decline sharply. Moreover, many agricultural import markets have tightened technical barriers and trade safeguard measures, requiring product traceability, issuing export certificates, inspecting goods and quality at exporting country. This also causes significant difficulties for enterprises purchasing and processing agricultural products.

Unpredictable disease developments have seriously affected the production of agricultural products. The situation often occurs: where it is needed, it is not available, where it is available, it cannot be consumed. The disruption of the supply chains of agricultural products is also a big barrier affecting the consumption of goods.

\section{Supply chain management and operations}

The term "supply chain management" appeared long ago and was commonly used in the 1990s [10]. According to Laura Rock Kopczak and M. Eric Johnson [3], in the early 1990s, supply chains were limited to managers of a few global companies who were having difficulty coordinating internal 
information and raw materials. Therefore, supply chain management is also understood in a very narrow sense. Over time, along with the development of science and technology and specialization in the production process, companies gradually realized that a single department or an individual company could not meet the needs of the customers. Customer needs that require the alignment of all members of the supply chain [1]. Supply chain management and operations are getting more and more attention. According to Lambert and Cooper (2000), supply chain management is the integration of business processes from consumers to suppliers of raw materials to create products, services, and information to benefit both customers and supply chain members. As such, a supply chain by this definition pertains to the life cycle of a product or service. Supply chain management is therefore an activity of many actors with close interrelationships and towards the ultimate goal of bringing value to customers.

For different products, the supply chain has different characteristics. In the agricultural sector, FAO [12] defines: "Agricultural value chain includes the set of actors and activities that bring an agricultural product from production to the final consumer, whereby the value of product is increased in each intermediate stage. A value chain can be a vertical link or a network of independent actors involved in processing, packaging, storage, transportation, and distribution. Activities in the value chain of agricultural products include production, collection, processing, wholesale and retail as well as supporting functions such as supply of inputs, financial services, logistics services, packaging, and marketing.

3. The relationship between technology and supply chain management

Along with the development of society, technology is also constantly changing. The great achievements of technology development include: the introduction of the internet of things (IoT); big data, artificial intelligence (data science); blockchain (blockchain); 3D printing technology (additive manufacturing); robotics technology, etc. [10]. Technology is not only a common term, but it is in fact related to supply chain management [11].

IoT is capable of connecting all customers, suppliers, etc. on technological devices [2]. IoT can collect large volumes of product and market related data from source to consumer and vice versa [10].

By combining customer data and their operations, data and AI technology can create a superior competitive advantage for companies [8]. AI technology helps to present information that reflects market needs and specific customer requirements. As changes in customer needs and preferences are captured and analyzed, new production and distribution technologies, especially 3D printing and robotics, will become more flexible [10].

Blockchain technology has the potential to significantly reduce the need for verification, thereby increasing the efficiency of supply chain management [10]. 3D printing could suggest new supply chain design options, whereby customers customize or personalize online orders and manufacturers can manufacture products in nearby factories and deliver goods to customers in very short cycle times [9]. The combination of computers with more powerful processors, the capture of detailed data through the IoT, and the use of AI has spurred the faster development and adoption of robots in a number of fields, creating new possibilities and potential improvements in supply chain planning, execution and control [6], [10].

Supply chain management from a modern customercentric perspective. Therefore, technology makes it possible for customers to experience many different purchasing methods. Through technology, customers can also know full information about products, prices, locations, promotions, etc. to make appropriate purchasing decisions [4], [10]. Technology will also make it possible for every customer to give feedback on their shopping experience with the product. Therefore, receiving good feedback from customers will help companies gain a competitive advantage. In addition to focusing on product development, companies need to focus on good supply chain management and operation design.

In summary, technology is a factor that has a huge impact and plays a particularly important role in supply chain management and operation.

\section{RESULT AND DISCUSSION}

1. The current situation of technology application in the management and administration of the supply chain of agricultural products in Vietnam during the Covid-19 pandemic

A. The current situation of Vietnamese agricultural products supply

In 2021, the fourth wave of Covid-19 epidemic broke out in Vietnam, many localities implemented social distancing, resulting in the supply chain of agricultural products in many localities being broken. According to VCCI Can Tho's statistics, in just 3 months, 7, 8, 9, the whole Mekong Delta region has over 10,000 enterprises leaving the market. In order for agricultural products to reach the end consumer, a complex supply chain with the participation of many parties must work together in harmony, only one link disruption will cause the whole chain to stall. During the current outbreak of disease in Viet Nam, not only one but many links in the supply chain of agricultural products have been broken.

According to 78/NQ-CP dated July 20, 2021 of the Government on the prevention and control of the Covid-19 pandemic, the Ministry of Agriculture and Rural Development (MARD) established the Southern Working Group (the 970) and Northern Working Group (the 3430) to coordinate with localities. According to statistics of MARD, the main indicators reflected are: Agriculture decreased by $2 \%$, of which the South decreased by more than $5.6 \%$, livestock decreased by $3.8 \%$. Aquaculture in August alone decreased by $7.4 \%$, pulling the overall situation to increase by $5.6 \%$. General statistics: Compared to July 2021, only 3 product groups increased: cassava and cassava products $(+26.6 \%)$, cereal products $(+1.1 \%)$, milk and products The rest of dairy products $(+0.8 \%)$ all dropped sharply in export value. The 
biggest decrease was in pangasius and shrimp products ($29.7 \%$ ), vegetables $(-25.8 \%)$, etc. The main cause was the Covid-19 epidemic which had a great impact on the production and processing activities of the company. many enterprises/factories for export processing, many enterprises/factories only operate at $30-40 \%$ capacity, even have to close due to F0.

Currently, there are 3 groups of agricultural products that are difficult to consume: fruits and vegetables, livestock products and aquatic products.

The specific situation in some important provinces is as follows: With crop products, Binh Duong currently has a surplus of about 80 tons of melons, 70 tons of bananas and 30 tons of seedless lemons. In particular, leafy vegetable products are in excess and facing difficulties in consumption. The complicated situation of the Covid-19 pandemic led to many material areas being blocked due to the distance, greatly affecting production and harvesting, and the capacity at seafood processing factories decreased to $50 \%$. According to data from the Tien Giang Statistics Department, in the first nine months of 2021, seafood exports of enterprises in the province only reached about 65.656 tons, down more than $23 \%$ over the same period; export value reached just over 144 million USD, reaching $45 \%$ of the plan, down $29 \%$ over the same period. In Ca Mau province, local reports said that due to the impact of the epidemic, the entrance and exit of the sea estuary was strictly controlled, the prices of fishery products decreased, some items decreased deeply $30-40 \%$ on average.

Reflected by Working Group 970 of MARD, in terms of seafood production in the southern provinces, there are not enough human resources to take part in caring, harvesting and transporting products. Due to the impact of the pandemic, employees do not want to participate, fearing infection, while the participants do not have medical conditions (have not been vaccinated, ...). In addition, labor does not or is difficult to move from one locality to another to care for and harvest products, increasing the risk of disruption in the production and supply chain from seed to commercial product. The supply of input materials (seedlings, feed, drugs, chemicals, products to treat and improve the aquaculture environment) did not respond in time, resulting in increased costs due to transshipment and COVID-19 testing. 19. The difficulty of calling and calling traders, factories to buy seafood, lack of drivers, means of transport ... has made the purchase price drop sharply, especially raw shrimp. Besides, MARD said that only $30 \%$ of seafood processing enterprises in the South operate with average capacity reduced to $30-35 \%$. Aquatic raw materials for processing and export only reach $40-50 \%$ compared to external raw materials. Currently, there are 15 aqua feed factories, 120 seafood processing factories with case F0 that have to stop operating.

B. The current status of technology application in the management and administration of the supply chain of agricultural products in Vietnam during the Covid-19 pandemic

Some cities are starting to accelerate the application of technology in the management and administration of the supply chain of Vietnamese agricultural products during the Covid-19 pandemic. Ho Chi Minh City is building a software to coordinate information on demand for agricultural products continuously in order to coordinate with southern provinces and cities providing food to produce according to the city's needs, creating close links in agriculture. Karma. Covid-19 has impacted farmers' awareness. In the past, wholesale market traders made all deliveries at the market, then distributed to the traditional market. But now, they trade through social networks. Sellers can ship directly to buyers via online platforms reducing costs and time. The epidemic has promoted e-commerce activities and technology application more.

In addition, the Ministry of Industry and Trade organized the implementation of a solution to apply blockchain technology in product traceability for a number of agricultural products in order to improve the brand and promote the export of agricultural products. production in developed countries in the context of the EVFTA agreement being ratified; Building a total solution for the logistics service exchange system between logistics service enterprises and agricultural product trading enterprises in order to facilitate delivery services associated with e-commerce; At the same time, the Ministry of Industry and Trade has digitized the market information system, upgraded the Vietnamese export support platform ECVN.com.

In general, the application of technology in the management and administration of the supply chain of agricultural products in Vietnam is only at the beginning stage and still lacks many legal frameworks and supports from the State.

2. Lessons learned from countries around the world in protecting and developing the supply chain of agricultural products during the Covid-19 pandemic

\section{A. Lessons from China}

China is a major producer and consumer of agricultural products in the world. When the Covid 19 pandemic occurred, it also impacted the supply chain of agricultural products of this country. However, to face the negative impacts on the agricultural sector, China has some adaptive solutions.

China has established a "green stream" and applied technology to market and distribute goods. When the Covid19 pandemic spread strongly in China, the country applied many blockade measures, causing the supply chain of agricultural products to be broken at many stages. At this point a series of measures are put in place to solve the problem. China's Ministry of Agriculture and Rural Affairs organizes online conferences to help businesses sell goods. Information and communication technology is fully utilized. The China Agricultural Products Market Association cooperates with a number of media platforms and e-commerce sites to set up an online service platform to support the sale of agricultural products during the pandemic. Besides the website platform, chat groups on mobile devices, WeChat accounts and 24/7 hotline are also available to provide necessary information related to the supply of agricultural products. In addition, an important platform is the online sale of agricultural products of poor areas, established by the Ministry of Finance and the 
Poverty Alleviation Department of the State Council, focusing on supporting disadvantaged localities.

In addition to supporting consumer online channels, the Chinese government also encourages e-commerce enterprises to actively participate in selling agricultural products. Many ecommerce businesses have initiated projects to support farmers, mobilizing various resources in purchasing, logistics, shipping and marketing to maximize benefits for both farmers and businesses. To drive sales, the platforms set up special sales portals with well-designed graphics and slogans like "take care of the farmers" and offer coupons and discounts to customers. agricultural transactions. In addition, they also use marketing tools such as live streams of short videos like tick Tok, using the influence of celebrities to introduce the good characteristics of agricultural products. The above solutions of the Chinese government have also had obvious effects in solving the problem of goods supply in this country.

\section{$B$. Lessons from Thailand}

Thailand has been making a significant contribution and plays an important role in international trade. Thailand is also a leading producer and exporter of agricultural products in the world. In the Covid 19 pandemic, Thailand is also a country that has strongly applied digital technology in goods supply chain management and operation, bringing positive effects. They use a number of digital technologies and electronic data systems to manage the supply of agricultural goods. The continuous development of technology and application of technology in the production and circulation of goods in Thailand allows supply chain activities to flow and be efficient. In addition, the digital economy is one of the core pillars of management in Thailand..., the "Digital Thailand Policy" was launched by the Thai Government with the ambition of building a digital society and economy, helping Thailand can become a "digital leader". Thailand plans to deploy broadband to every village, providing 10,000 free WiFi points, doubling international bandwidth.

Investment in building smart cities is also an important focus of Thailand to promote agriculture and tourism industry, contributing to narrowing income gap, promoting economic growth.

During the covid 19 pandemic, the increase of blockchains has brought about significant efficiencies in the supply of agricultural goods: goods supply companies can verify goods supply information in a more efficient way. Businesses can also verify their products for foreign customers easily. Technology can also automate activities in the agricultural supply chain in Thailand. For example, factories and enterprises only need 2 to 3 people to operate machines, which helps to cut production costs and improve production efficiency. In addition, thanks to the application of technology in price management of agricultural products in Thailand, which are updated online, traders and exporters can optimize their profits. Besides, digitization such as e-commerce and online shopping has opened new doors for the agricultural product market in Thailand in foreign markets such as China, ASEAN countries, the United States and the EU.

3. Lessons for Vietnam and recommendations

\section{A. Lessons for Vietnam}

From practical experience in China and Thailand on applying technology in supply chain management of agricultural products, Vietnam also needs lessons in chain management and operation:

From Thailand's experience, to succeed, it is necessary to define the digital economy as not merely promoting the development of information technology but also a comprehensive digitalization process in the production and supply of agricultural products. Therefore, there is a need for a consensus on the position, role and connotation of the digital economy in policy formulation and making, especially in government agencies. From there, there is an accurate positioning and orientation, right on the agenda for the digital economy, as well as a reasonable and effective allocation of resources for implementation in reality.

Vietnam needs to focus on training and developing information technology human resources. The information technology human resource training program should aim to accelerate the socialization of information technology education, especially updating information technology training curricula in association with new technology trends, such as IoT, artificial intelligence, robotics. In particular, it is necessary to build a core digital workforce, sufficient in quantity and satisfying in quality to serve the requirements of digitizing all areas of social life from agriculture to industry and services. service.

From practical experience in China, Vietnam also needs to make flexible adaptations in applying technology to supply goods such as: applying internet software, organizing a series of introduction events, supplying goods to customers. digitalization helps businesses find their customers. Guide farmers can use e-commerce to sell goods instead of the traditional way of supplying goods as before. That will promote a smooth supply chain of goods and minimize disruptions in circulation.

\section{B. Recommendations}

Firstly, Build a brand development strategy for Vietnamese agricultural products. Currently, Vietnamese agricultural products are exported to foreign countries mainly in the role of processors and exporters. Local brands occupy the most profitable position in the value chain. They are the importers and distributes to the end customer in the host country. The government and Vietnamese agricultural product exporters need to work together to make more and more Vietnamese brands occupy the last position in this supply chain. Businesses can be more active in participating in the Intellectual Property Development Support Program of the National Office of Intellectual Property of Vietnam. Initially, businesses can join the association, develop a joint brand with a local retailer, then gradually expand and build their own brand.

Secondly, promote linkages in agricultural areas for Vietnamese agricultural products. Regional linkage is the connection between members in the region and between members in the region with other members outside the region. This is a solution for specialization among localities in the 
region, focusing on effectively exploiting the strengths of each locality, closely linking in the value chain of agricultural products from production investment to consumption. Localities can set up working groups of each province to connect and solve problems on production and consumption of agricultural products in the area; coordinate with localities to promote the circulation and consumption of agricultural products between provinces and cities in the region.

Third, promote the application of high technology and digital transformation in the supply chain of agricultural products. This application should be invested by businesses trading and distributing agricultural products synchronously or linked with a group of businesses in the region to perform at all stages such as: 1-Strengthening the stamping with QR codes for source traceability origin of agricultural products. This QR code should be detailed to identify each farmer household, quantify the type of fertilizer, and date and time to use chemicals in farming. 2-Building a set of rules for production, digitization and aggregation into a data warehouse and uniformly applied to all units participating in the chain. 3-Associating logical infrastructure with the access chain in terms of time and location of delivery. 4-Build your own e-commerce platform or cooperate more with domestic e-commerce products.

Fourth, build short supply chains according to regional links. Some forms of short supply chain of agricultural products are suitable in Vietnam, such as: Model of selling products directly from producer, farm to consumer, model through an intermediary stage of production cooperatives. agricultural production with the motto of investment, direct purchase of agricultural products and supply in large quantities to industrial parks, collective kitchens of schools, agencies and hospitals. The state needs to develop a legal framework, mechanisms and policies for short supply chains, to avoid the current situation where models develop spontaneously, with no agency responsible for specific management.

\section{Conclusion}

The Covid-19 pandemic has greatly affected the process of globalization in general and the increasingly complex supply chain flows in the world in particular. However, the adoption of the latest technologies in commodity supply chain management seems to be an irreversible trend. Agricultural goods are also not out of that game. Whether Vietnamese agricultural products can occupy a higher position in the global value chain is a difficult question. And technology is an important link that businesses as well as managers and policy makers need to use to solve that problem.

\section{REFERENCES}

[1] Barratt, M., Barratt, R. (2012). "Exploring internal and external supply chain linkages: Evidence from the feld", Journal of Opreations Management, 29 (5), 514-528.

[2] Kranz, M. 2017. "Success with the Internet of Things Requires More Than Chasing the Cool Factor", Harvard Business Review.

[3] Laura Rock Kopczak and M. Eric Johnson. (2003), "The supply-chain management Effect", Mit Sloan management review (Spring 2003), 27-34.

[4] Lambert, D. M., Cooper, M. C. (2000). "Issues in Supply Chain Management",

Journal of Industrial Marketing Management, 29 (1), 65-83.

[5] Nguyen Thi Tan Loc (2016), Research on vegetable consumption through markets and supermarkets in Hanoi city. Doctoral thesis in Economics, Vietnam Academy of Agriculture.

[6] Nguyen Van Ngoc, Dictionary of Economics, National Economics University

[7] Renma M.A. Singnore, F. F. Montesono, M. Gonnella \& P. Santamaria (2019). "Biodiversity of vegetable Crops, A Living Heritage", Agriculture 2019, 9, 47, Retrieved from http://doi.org/10.3390/agriculture9030047 on 13/10/2021.

[8] Sanders, N.R. 2016. "How to Use Big Data to Drive Your Supply Chain", California Management Review 58(3):26-48.

[9] Sodhi, M.S., and Tang, C.S. (2017). "Social Responsibility in Supply Chains" New York: Springer, 465-83.

[10] Soonhong Min, Zach G. Zacharia, and Carlo D. Smith, 2019. "Defining Supply Chain Management: In the Past, Present, and Future”, Journal of Business Logistics, 2019, 40(1): 44-55

[11] Waller, M.A., and Fawcett, S.E. (2014). "Click Here to Print a Maker Movement Supply Chain: How Invention and Entrepreneurship Will Disrupt Supply Chain Design", Journal of Business Logistics 35(2):99-102.

[12] FAO (2010), "Agricultural Value Chain Finance. Tools and Lessons", Retrieved from http://www. https://www.fao.org/policy-support/toolsand-publications/resources-details/en/c/423759/ on 21/11/2021

[13] FAO (1998). "Basic understanding of horticulture", Retrieved from http://www.fao.org/3/x5642e/x5642e06.htm on 13/10/2021. 